\title{
RNAi targeting of hTERT gene expression induces apoptosis and inhibits the proliferation of lung cancer cells
}

\author{
LINHU GE ${ }^{1,2,3}$, WENLONG SHAO ${ }^{2,3}$, YANGDE ZHANG ${ }^{1}$, YUAN QIU ${ }^{2,3}$, \\ DONG CUI $^{2,3}$, DONGHAI HUANG ${ }^{2,3}$ and ZHANSHENG DENG ${ }^{1}$ \\ ${ }^{1}$ Department of Surgery, Xiangya Hospital, Central-South University, Changsha 410008; \\ ${ }^{2}$ Department of Cardiothoracic Surgery, The First Affiliated Hospital of Guangzhou Medical College, \\ Guangzhou 510182; ${ }^{3}$ Guangzhou Institute of Respiratory Disease and China State Key \\ Laboratory of Respiratory Disease, Guangzhou 510120, P.R. China
}

Received January 21, 2011; Accepted July 28, 2011

DOI: 10.3892/ol.2011.388

\begin{abstract}
The present study aimed to investigate the effects of RNAi-mediated reduction in human telomerase reverse transcriptase (hTERT) expression on apoptosis and lung cancer cell proliferation. A number of cell lines, including 95D, were used. hTERT mRNA levels were detected, and the RNA concentration was calculated. MTT assay was used to detect the inhibition of cell proliferation. The siRNA with the highest suppression rate, siRNA-1, was transfected into 95D cells at three different concentrations (50, 80 and $100 \mathrm{nmol} / \mathrm{l})$. The levels of hTERT mRNA in cells transfected with $50 \mathrm{nmol} / 1$ siRNA-1 were not significantly different from those of the negative controltransfected cells $(\mathrm{P}>0.05)$, whereas both 80 and $100 \mathrm{nmol} / \mathrm{l}$ siRNA-1 showed significant reductions in hTERT mRNA compared to the negative control cells $(\mathrm{P}<0.01)$. hTERT levels in the 80 - and 100-nmol/1 groups were not significantly different $(\mathrm{P}>0.05)$. Compared with the control cells, cells transfected with 50,80 or $100 \mathrm{nmol} / 1$ siRNA-1 showed higher fractions of apoptotic cells $48 \mathrm{~h}$ post-transfection $(\mathrm{P}<0.01)$, although the apoptotic fraction in cells transfected with $50 \mathrm{nmol} / 1$ siRNA-1 was not significantly different compared to that in cells transfected with negative control siRNAs $(\mathrm{P}>0.05)$. Moreover, the 80- and 100-nmol/l-transfected cells showed significantly increased apoptotic indices $(\mathrm{P}<0.01)$. MTT results indicated a time-dependent inhibition of siRNA-1transfected cell proliferation starting at $12 \mathrm{~h}$ and lasting through $48 \mathrm{~h}$ post-transfection; the inhibition was attenuated by $72 \mathrm{~h}$ post-transfection. The high levels of hTERT mRNA in all human lung cancer cell lines tested suggest that telomerase plays a role in lung carcinogenesis, and this hypothesis was strengthened by the data showing that the siRNA-mediated reduction in hTERT
\end{abstract}

Correspondence to: Dr Zhansheng Deng, Department of Surgery, Xiangya Hospital, Central-South University, No. 87, Xiangya Rd, Changsha 410008, P.R. China

E-mail: drdeng2010@yeah.net

Key words: lung cancer, human telomerase reverse transcriptase, siRNA-1, apoptosis, proliferation
mRNA caused apoptosis and an inhibition of the proliferation of lung cancer cells.

\section{Introduction}

Telomeres are disposable DNA sequences that preserve chromosomal integrity during mitosis. Human telomerase is a ribonucleoprotein comprising human telomerase RNA (hTR) and related proteins, which prevents telomere degradation, loss, rearrangement or end-to-end fusion (1). One of these related proteins, human telomerase reverse transcriptase (hTERT), uses hTR as a template to continuously synthesize telomeric DNA sequences at the ends of chromosomes. Although telomerase activity in normal cells is only detected in cells with proliferative potential, such as germ line and hematopoietic cells, as well as activated lymphocytes (2), the majority of malignant carcinoma cells exhibit telomerase activity. For example, telomerase activity is detected in up to $80 \%$ of non-small cell lung carcinoma cells $(3,4)$, suggesting that the inhibition of telomerase activity in tumor cells blocks telomeric repair, leading to a gradual reduction in telomere length during each round of replication and subsequent cell senescence and death. Therefore, telomerase has received much attention in the investigation into cancer treatment strategies. Studies $(5,6)$ have confirmed that telomerase inhibition by approaches including the use of exogenous antisense oligonucleotides are capable of inhibiting intracellular telomerase activity and therefore blocking cell growth and inducing apoptosis.

In the present study, 95D giant-cell lung carcinoma cells, which exhibit a high hTERT expression, were used for RNAi experiments, wherein siRNAs specifically targeting hTERT mRNA were transfected into cells and the effects of hTERT reduction on tumor cell growth and proliferation were analyzed. This study provides experimental evidence for the application of RNAi technology to the treatment of lung cancer and also provides new data on the role of telomerase in lung cancer.

\section{Materials and methods}

Materials. The following cells were used in this study: L78 and NCI-H520 human squamous cell lung cancer cells, A549 
Table I. The primer sequences and lengths of the amplified hTERT and $\beta$-actin PCR fragments.

\begin{tabular}{lccc}
\hline Gene & & Primer sequences & Lengths (bp) \\
\hline hTERT & Upstream primers & 5'-GCGTTTGGTGGATGATTTCT-3' & 131bp \\
& Downstream primers & 5'-CAGGGCCTCGTCTTCTACAG-3' & \\
& Upstream primers & 5'-TTCCTGGGCATGGAGTCCT -3' & 187bp \\
& Downstream primers & 5'-TGATCTTCATTGTGCTGGGTG-3' \\
\hline
\end{tabular}

and LTEP- $\alpha-2$ human lung adenocarcinoma cells, NCI-H460 large-cell lung cancer cells, 95D giant-cell lung carcinoma cells, 3T3 mouse embryonic fibroblasts and 293T human embryonic kidney cells. Cells were provided by and stored in the National Key Laboratory of Respiratory Diseases, Guangzhou, China. The PCR primers for the amplification of the hTERT and $\beta$-actin (internal control) genes were designed using Primer 5 software, and the specificity was confirmed by GenBank Blast analysis. The primers were commercially synthesized (Invitrogen, Shanghai, China) and diluted to $10 \mu \mathrm{M}$ using RNase-free water prior to use. The primer sequences and lengths of the amplified fragments are shown in Table I.

Detection of hTERT mRNA levels. For each cell line, vials of cells were retrieved from liquid nitrogen, placed in a $37^{\circ} \mathrm{C}$ water bath and agitated frequently to rapidly thaw the cells. The cells were then transferred to a centrifuge tube with 10 volumes of complete cell culture medium and pelleted by low-speed centrifugation. The supernatant was then removed and the cells were washed once with culture medium. The cells were diluted in fresh culture medium, seeded into flasks and incubated at $37^{\circ} \mathrm{C}$. The following day, the medium was changed and the cells were continually cultured.

To passage the cells, the culture medium was aspirated from the flask, $1 \mathrm{ml}$ trypsin was added and the flask was gently swirled to cover all of the cells with trypsin. The cells were incubated with trypsin for 2 to $5 \mathrm{~min}$, during which time the cells were observed by microscopy. Once the cytoplasms had shrunk and the spaces between cells were enlarged, an equal volume of culture medium with $10 \%$ fetal bovine serum was added immediately to stop trypsinization. The cells were pipetted up and down repeatedly until all of the cells were dislodged and suspended. The cells were then seeded into new flasks and fresh medium containing serum was added.

To freeze cells for storage, uncontaminated cells in the exponential phase of growth were selected and fed with fresh medium one day prior to freezing. The cells were then trypsinized and collected as previously described and then pelleted by centrifugation at $1000 \mathrm{rpm}$ for $10 \mathrm{~min}$. The supernatant was removed gently and the cells were resuspended in cell freezing medium. The suspension was transferred to 2-ml cryovials and gradually frozen by first cooling at $4^{\circ} \mathrm{C}$ for $10 \mathrm{~min}$, then freezing at $-20^{\circ} \mathrm{C}$ for $2 \mathrm{~h}$ and finally transferring the cells to $-70^{\circ} \mathrm{C}$ for storage.

Extraction of total RNA from lung cancer cells. The culture medium from healthy lung cancer cells $\left(1 \times 10^{6}\right)$ was aspirated, and the cells were washed with PBS and then directly lysed by adding $1 \mathrm{ml}$ TRIzol reagent to the culture flask. After pipetting several times, the cells were incubated at room temperature for $5 \mathrm{~min}$, transferred into 1- $\mathrm{ml}$ microfuge tubes, inverted 10 times and held at room temperature for $2 \mathrm{~min}$. For every $1 \mathrm{ml}$ TRIzol, $0.2 \mathrm{ml}$ chloroform was added to the microfuge tube, and the cells were mixed by vortexing for $15 \mathrm{sec}$ to completely mix the solutions. The tube was held at room temperature for $5 \mathrm{~min}$, and the solution was separated into three layers by centrifugation at $12,000 \mathrm{xg}$ for $15 \mathrm{~min}$ at $4^{\circ} \mathrm{C}$.

After centrifugation, the top aqueous phase containing the RNA was transferred into a new $1.5-\mathrm{ml}$ microfuge tube and $0.5 \mathrm{ml}$ isopropanol was added (a 0.5:1 ratio of isopropanol:TRIzol). The tube was inverted 5 times to mix the solutions and then held at room temperature for $10 \mathrm{~min}$. The mixture was then separated by centrifugation at $12,000 \mathrm{x}$ g for $10 \mathrm{~min}$ at $4^{\circ} \mathrm{C}$. The supernatant was carefully removed, leaving the pellet intact. Pre-chilled $75 \%$ ethanol $(1 \mathrm{ml}$; prepared by diluting in RNase-free water) was added to each tube. The tube was gently agitated and then separated by centrifugation at 7,500 $\mathrm{x} \mathrm{g}$ for $5 \mathrm{~min}$ at $4^{\circ} \mathrm{C}$. The supernatant was discarded, and as much of the residual ethanol was removed as possible. The microfuge tube was placed in a vacuum dryer for approximately $2 \mathrm{~min}$, or until the RNA pellet became transparent. Depending on the size of the RNA pellet, 20-40 $\mu$ l RNase-free water was added to the tube to dissolve the RNA pellet; an RNase inhibitor was also added at a ratio of 1:30. The purity of the isolated RNA was then assessed by spectrometry; the optical density (OD) ${ }_{260} / \mathrm{OD}_{280}$ of the samples was between 1.8 and 2.0, indicating little protein contamination and a high purity that was ideal for our experiments. The integrity of the RNA was also examined by $2 \%$ agarose gel electrophoresis.

The RNA concentration was calculated based on the $\mathrm{OD}_{260}$ value using the formula: concentration of $\mathrm{RNA}=\mathrm{OD}_{260}$ value $\mathrm{x}$ dilution factor $\mathrm{x} 40 \mu \mathrm{g} / \mathrm{ml}$. Based on this calculation, total RNA was further diluted to $1000 \mathrm{ng} / \mu \mathrm{l}$ using RNase-free water for convenience during the reverse transcription reaction, which was performed immediately. The remaining RNA was stored at $-80^{\circ} \mathrm{C}$.

Reverse transcription. For each sample, $1 \mu \mathrm{g}$ total RNA was used for the reverse transcription reaction (reaction mixture are shown in Table II) using a PCR thermocycler (Biometra, T-personal 48, Germany) and the PrimeScript RT reagent kit (Takara, Japan). The reverse transcription reaction was performed at $37^{\circ} \mathrm{C}$ for $15 \mathrm{~min}$, and the reaction was terminated by heating to $85^{\circ} \mathrm{C}$ for $5 \mathrm{sec}$.

Optimization of PCR conditions. Different annealing temperatures and PCR cycle parameters were tested to optimize the 
Table II. Reverse transcription reaction mixtures.

\begin{tabular}{lrc}
\hline Reagents & Dose $(\mu \mathrm{l})$ & $\begin{array}{c}\text { Final } \\
\text { concentration }\end{array}$ \\
\hline 5X PrimeScript ${ }^{\mathrm{TM}}$ Buffer & 4.0 & $1 \mathrm{X}$ \\
PrimeScript ${ }^{\mathrm{TM}}$ RT Enzyme Mix I & 1.0 & \\
Oligo dT primer & 1.0 & $25 \mathrm{pmol} / 1$ \\
Random 6 mers & 1.0 & $50 \mathrm{pmol} / 1$ \\
RNase-free $\mathrm{dH}_{2} \mathrm{O}$ & 12.0 & \\
Total RNA $(1000 \mathrm{ng} / \mu \mathrm{l})$ & 1.0 & $50 \mathrm{ng} / \mu \mathrm{l}$ \\
\hline
\end{tabular}

PCR conditions, which were critical for our experiments. The PCR conditions used for optimization were: initial DNA denaturation at $95^{\circ} \mathrm{C}$ for $15 \mathrm{~min}$ and then 40 cycles of denaturation at $94^{\circ} \mathrm{C}$ for $60 \mathrm{sec}$, annealing at $58^{\circ} \mathrm{C}$ for $60 \mathrm{sec}$ and elongation at $72^{\circ} \mathrm{C}$ for $60 \mathrm{sec}$, followed by a final elongation step at $72^{\circ} \mathrm{C}$ for $10 \mathrm{~min}$. The annealing temperature was the parameter that best reflected the specificity of the target gene. During annealing temperature optimization, four annealing temperatures, $55^{\circ} \mathrm{C}$, $56^{\circ} \mathrm{C}, 57^{\circ} \mathrm{C}$ and $58^{\circ} \mathrm{C}$, were used for the regular PCR experiment based on the theoretical annealing temperature calculated by the Primer 5 software (reaction mixture shown in Table III). For optimization of the cycle number for target gene amplification, PCR experiments were performed with 20-40 cycles, differing by increments of 4 . The PCR products were analyzed by agarose gel electrophoresis to detect the specific amplified products.

Analysis of regular PCR products. Each PCR product $(2 \mu \mathrm{l})$ was separated by electrophoresis using a $1.0 \%$ agarose gel containing ethidium bromide $(0.5 \mu \mathrm{g} / \mathrm{ml})$ for $40 \mathrm{~min}$ at $100 \mathrm{~V}$. The DL2000 DNA marker (ShineGene, Shanghai, China) was used as the molecular standard, and the gel was observed under UV light.

Detection of the relative levels of $h T E R T M R N A$. For each sample, $1 \mu \mathrm{l}$ cDNA was used for RT-PCR using the SYBRGreen I method (the reaction mixture is shown in Table IV) to detect the relative expression levels of hTERT mRNA. The reaction conditions were optimized according to the steps described previously in this section. The reaction conditions used to detect hTERT levels were: initial DNA denaturation at $95^{\circ} \mathrm{C}$ for $15 \mathrm{~min}$ and then 40 cycles of denaturation at $94^{\circ} \mathrm{C}$ for $15 \mathrm{sec}$, annealing at $58^{\circ} \mathrm{C}$ for $30 \mathrm{sec}$ and elongation at $72^{\circ} \mathrm{C}$ for $15 \mathrm{sec}$.

The $\mathrm{Ct}$ values for the hTERT and $\beta$-actin genes in each sample were determined. After normalization to the internal control gene, the data were analyzed by using the $2^{-\Delta \Delta \mathrm{Ct}}$ method (5), in which $\Delta \mathrm{Ct}=\mathrm{Ct}($ hTERT $)-\operatorname{Ct}(\beta$-actin $)$ and $\Delta \Delta \mathrm{Ct}=$ $\Delta \mathrm{Ct}_{\text {sample group }}-\Delta \mathrm{Ct}_{\text {control group }}$. The relative level of hTERT mRNA was $2^{-\Delta \Delta C t}$.

Transfection of hTERT siRNAs and the analysis of the effects of hTERT knockdown: design and synthesis of siRNAs. Based on the hTERT gene sequence in Genbank (NM_003219, NM_198253,NM_198254 and NM_198255) and following the rules of siRNA design, three pairs of 21-bp siRNAs
Table III. PCR reaction mixtures.

\begin{tabular}{lcc}
\hline Reagents & Dose $(\mu \mathrm{l})$ & $\begin{array}{c}\text { Final } \\
\text { concentration }\end{array}$ \\
\hline Premix Ex Taq $^{\mathrm{TM}}(2 \mathrm{X})$ & 10.0 & $1 \mathrm{X}$ \\
Upstream primers $(10 \mu \mathrm{M})$ & 0.4 & $0.2 \mu \mathrm{mol} / 1$ \\
Downstream primers $(10 \mu \mathrm{M})$ & 0.4 & $0.2 \mu \mathrm{mol} / 1$ \\
cDNA solution & 1.0 & \\
$\mathrm{ddH}_{2} \mathrm{O}$ & 8.2 & \\
\hline
\end{tabular}

Table IV. Quantitative real-time RT-PCR reaction mixtures.

\begin{tabular}{lcc}
\hline Reagents & Dose $(\mu \mathrm{l})$ & $\begin{array}{c}\text { Final } \\
\text { concentration }\end{array}$ \\
\hline Premix Ex Taq & & $1 \mathrm{X}$ \\
Upstream primers $(10 \mu \mathrm{M})$ & 10.0 & $0.2 \mu \mathrm{mol} / 1$ \\
Downstream primers $(10 \mu \mathrm{M})$ & 0.4 & $0.2 \mu \mathrm{mol} / 1$ \\
cDNA solution & 1.0 & \\
RNase Free $\mathrm{dH}_{2} \mathrm{O}$ & 8.2 & \\
\hline
\end{tabular}

were engineered. These siRNAs were then synthesized by Ambion (Austin, TX, USA): siRNA-1 sense strand: 5'-GGA ACACCAAGAAGUUCAU-TT-3' (1521-1539) and anti-sense strand: 5'-AUGAACUUCUUGGUGUUCC-TT-3'; siRNA-2 sense strand: 5'-CGCUCUUUUUCUACCGGAA-TT-3' (17691787) and anti-sense strand: 5'-UUCCGGUAGAAAAAGA GCC-TT-3'; siRNA-3 sense strand: 5'-GGUCUUUCUUUUA UGUCAC-TT-3' (1728-1746) and anti-sense strand: 5'-GUGA CAUAAAAGAAAGACC-TT-3'.

The Basic Local Alignment Search Tool (http://www.ncbi. nlm.nih.gov/BLAST/) was used to confirm that the sequences were not homologous to other genes. In addition, non-specific negative control siRNAs were also designed and synthesized. siRNAs were labeled with red fluorescent protein for the visual detection of transfection efficiency.

Transfection of hTERT siRNAs into lung cancer cells. siRNAs were delivered into the target cells using a reverse transfection method. Different concentrations of siRNA were transfected using the cationic liposome transfection reagent siPORT NeoFX (Ambion) into the target cells as per the manufacturer's instructions using $50 \mathrm{nmol} /$ well siRNA in 12-well plates as follows: lung cancer cells in the exponential phase of growth were trypsinized and suspended in antibiotic-free OPTI-MEM (Invitrogen, Carlsbad, CA, USA). The cell density was adjusted to $1 \times 10^{5} / \mathrm{ml}$ and stored in a culture incubator at $37^{\circ} \mathrm{C}$ with $5 \%$ $\mathrm{CO}_{2}$ until use.

In $47 \mu \mathrm{l}$ OPTI-MEM, $3 \mu \mathrm{l}$ siPORT NeoFX was added and then incubated at room temperature for $10 \mathrm{~min}$. In $47.5 \mu \mathrm{l}$ OPTI-MEM, $2.5 \mu 120 \mu \mathrm{M}$ siRNA was added, and the above two solutions were mixed to form transfection complexes; held at room temperature for $20 \mathrm{~min}$.

In each well of the 12 -well plate, $900 \mu 1$ cell suspension was added, followed by $100 \mu \mathrm{l}$ transfection mixture. The plate 
A

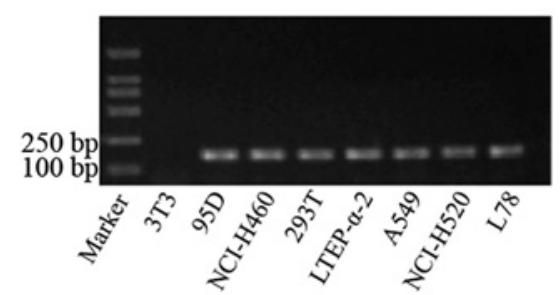

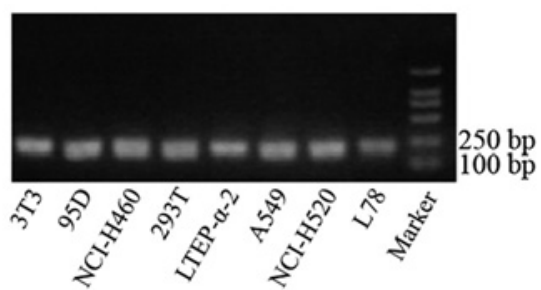

Figure 1. The electrophoresis results of the PCR products of (A) hTERT and (B) $\beta$-actin.

was gently agitated and then incubated for $6 \mathrm{~h}$, after which the medium was replaced. After $48 \mathrm{~h}$, red fluorescent protein expression was observed in the cells using an inverted fluorescent microscope to estimate the transfection efficacy.

Detection of hTERT mRNA levels. Total RNA was extracted from the transfected lung cancer cells after $48 \mathrm{~h}$, and the hTERT expression levels were measured by real-time PCR using the 2- $\Delta \Delta \mathrm{Ct}$ method described previously. The siRNAmediated suppression rate of hTERT mRNA was calculated as follows: suppression rate $(\%)=(1-$ the relative level of hTERT mRNA in the siRNA-transfected group $\div$ the relative level of hTERT mRNA in the negative control group) $x 100 \%$ (6).

Analysis of cell apoptosis. The 95D cells were transfected with $100 \mathrm{nmol} / \mathrm{l} \mathrm{siRNA}$, and the cells were harvested after $48 \mathrm{~h}$ using EDTA-free trypsin. The cells were then washed twice with PBS and pelleted by centrifugation (2000 rpm for 5 min per wash); $1-5 \times 10^{5}$ cells were harvested. Cells were resuspended in $500 \mu \mathrm{l}$ binding buffer, and $5 \mu \mathrm{l}$ annexin V-EGFP was added, followed by $5 \mu \mathrm{l}$ propidium iodide (PI). The solutions were mixed well and held in the dark at room temperature for 5 to $15 \mathrm{~min}$. The cells were then analyzed by flow cytometry; the green fluorescence of annexin V-EGFP was detected using the FITC channel (FL1) and the PI red fluorescence was detected through the PI channel (FL2 or FL3).

The MTT assay was used to detect the inhibition of cell proliferation by hTERT siRNA in lung cancer cells. Cells in the exponential phase of growth were transfected in 96-well plates, where each well contained $200 \mu 1$ cell culture. At 12 , 24, 48 and $72 \mathrm{~h}$ after transfection, $20 \mu \mathrm{l}$ MTT $(5 \mathrm{mg} / \mathrm{ml})$ was added to each well and the plate was incubated at $37^{\circ} \mathrm{C}$ with $5 \% \mathrm{CO}_{2}$ for $4 \mathrm{~h}$. The culture medium was then removed and $150 \mu 1 \mathrm{DMSO}$ was added in each well. The plate was agitated for $10 \mathrm{~min}$ and then read by a plate reader for the absorbance (A) at $570 \mathrm{~nm}$; the experiment was repeated three times. The inhibition rate of cell proliferation $=(1-$ the average $\mathrm{A}$ of the experimental group $\div$ the average $\mathrm{A}$ of the control group) x $100 \%$.

Statistical analysis. SPSS12.0 software was used for the statistics analysis. The experimental data are shown as the mean \pm standard deviation. Where the data followed a normal distribution with equal variance, one-way analysis of variance (ANOVA) was used to compare the means of multiple samples, and the LSD-t test was used for the pair-wise comparison of the means of multiple samples. For the comparison of the means of two independent samples, the paired t-test was used. $\mathrm{P}<0.05$ was considered to be statistically significant.

\section{Results}

Observation of the growth of lung cancer cells. By microscopic observation, lung cancer cells grew well and adhered to the bottom of the culture flask. The cells exhibited irregular polygonal spindle or oval shapes, the cytoplasms were transparent and the nuclei indistinct. Cells manifesting these morphological characteristics were collected for total RNA extraction, RT-PCR and quantification.

Detection of hTERT levels in lung cancer cells. The annealing temperature for the amplification of the hTERT and $\beta$-actin genes was $58^{\circ} \mathrm{C}$, since our results showed that non-specific amplification could be avoided at this temperature. In determining the optimum number of cycles, the intensity of the target gene band increased at an exponential rate after 30 to 40 amplification cycles, demonstrating that the amplification products increased exponentially. Cycle numbers greater than 40 caused enzyme saturation and a plateau effect; therefore, the optimized PCR protocol used 40 cycles. The electrophoresis results of the PCR products of hTERT and $\beta$-actin are shown in Fig. 1.

Detection of the relative levels of hTERT $m R N A$ in lung cancer cell lines. The levels of hTERT expression were detected in multiple lung cancer cell lines, including L78 and NCI-H520 human squamous cell lung cancer cells, A549 and LTEP- $\alpha-2$ human lung adenocarcinoma cells, NCI-H460 large-cell lung cancer cells and 95D giant-cell lung carcinoma cells. The 3T3 mouse embryonic fibroblast cell line does not express hTERT and was therefore used as the negative control, and 293T human kidney cells, which are known to express hTERT, were used as the positive control. The real-time quantitative PCR amplification curves of the target gene are shown in Fig. 2.

After statistical calculation, 95D human giant-cell lung carcinoma cells showed the highest relative level of hTERT mRNA, followed by NCI-H460 large-cell lung cancer cells (Fig. 3). The levels of hTERT mRNA in these two cell lines exceeded those in the squamous cancer and adenocarcinoma cell lines tested. Based on these data, the 95D cell line was selected for the RNAi experiments.

Detection of the effects of hTERT siRNAs on hTERT $m R N A$ levels. To knock down hTERT levels, 95D cells were 


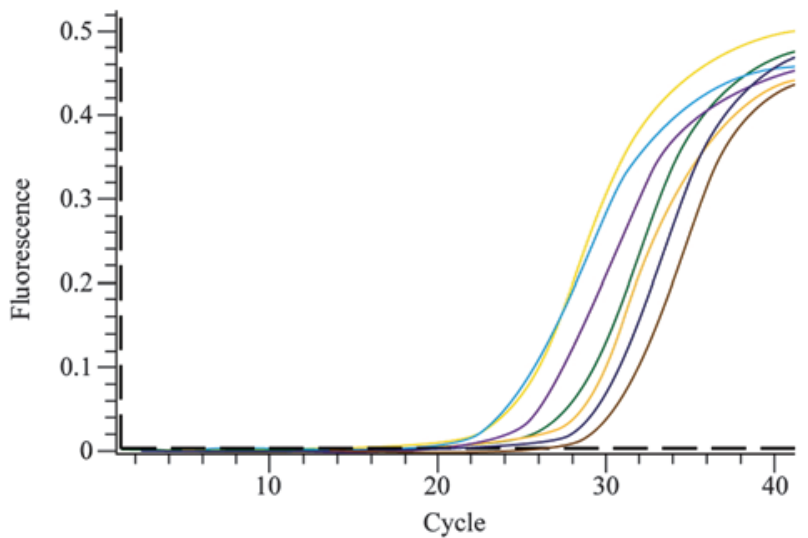

Figure 2. The real-time quantitative PCR amplification curves of the target gene (3T3, 95D, NCI-H460, 293T, LTEP- $\alpha-2$, A549, NCI-H520 and L78, from left to right).

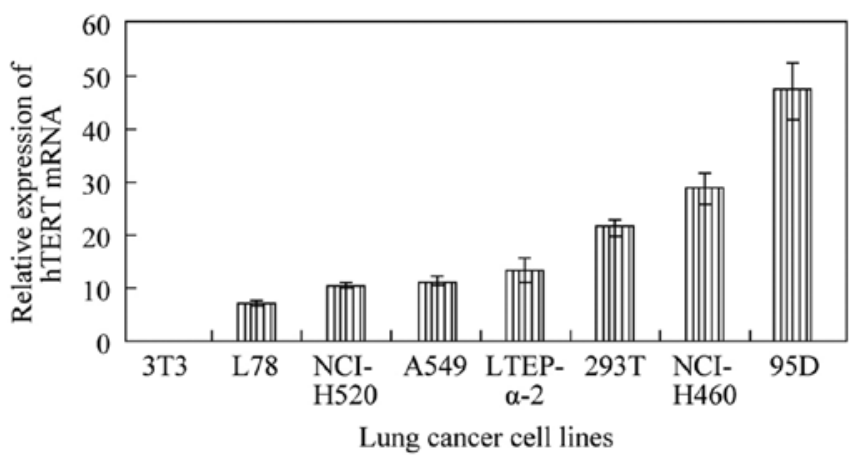

Figure 3. The relative levels of hTERT mRNA in different cell lines.

transfected with hTERT or control siRNAs. After $24 \mathrm{~h}$, the majority of control siRNA-transfected cells remained adherent to the culture flask and showed no change in cell morphology (Fig. 4A), indicating that the transfection caused little cytotoxicity. By fluorescent microscopy, transfected 95D cells fluoresced red, whereas non-transfected cells were not detected (Fig. 4B). Subsequently, the reverse siRNA transfection efficacy was estimated to be greater than $90 \%$, which is ideal for optimal target gene knockdown.

Detection of hTERT $m R N A$ levels in cells after transfection of hTERT siRNAs. The level of hTERT mRNA was significantly reduced $(\mathrm{P}<0.01) 48 \mathrm{~h}$ after transfection in 95D cells transfected with either siRNA-1 or siRNA-2 compared to cells transfected with either the liposome alone or with the negative control siRNA. The level of hTERT mRNA in cells transfected with siRNA-3 was also significantly decreased $(\mathrm{P}<0.05)$. Further calculations showed that the hTERT suppression rate in cells transfected with siRNA-1 and siRNA-2 was $77.33 \pm 5.13$ and $50.67 \pm 8.02 \%$, respectively, whereas the suppression rate was only $27.67 \pm 10.26 \%$ in cells transfected with siRNA-3 (Fig. 5). Due to the highest hTERT mRNA suppression rate, siRNA-1 was selected for the subsequent experiments.

The siRNA dose-dependent changes in hTERT expression in lung cancer cells. Cells were transfected with three different
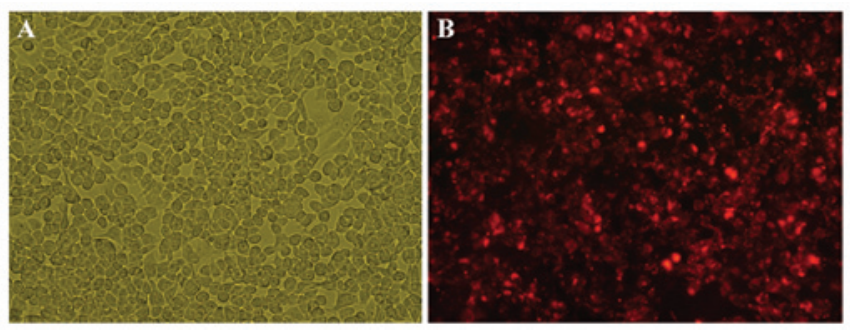

Figure 4. 95D cells were transfected with (A) hTERT or (B) control siRNAs

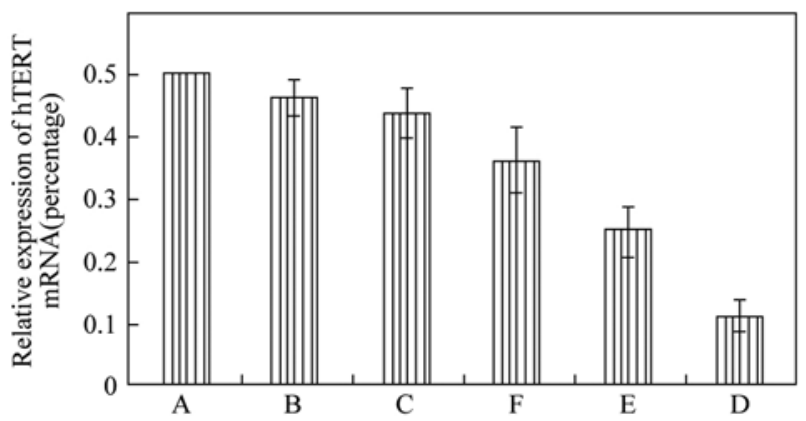

Figure 5. hTERT expression levels in lung cancer cells transfected with hTERT siRNAs of different concentrations.

Table V. hTERT expression levels in lung cancer cells transfected with hTERT siRNAs of different concentrations.

\begin{tabular}{lc}
\hline Groups & $\begin{array}{c}\text { Relative expression } \\
\text { of hTERT mRNA }\end{array}$ \\
\hline Negative control & $0.87 \pm 0.08$ \\
$50 \mathrm{nmol} / 1 \mathrm{siRNA}$ & $0.75 \pm 0.06$ \\
$80 \mathrm{nmol} / 1 \mathrm{siRNA}$ & $0.35 \pm 0.11^{\mathrm{a}}$ \\
$100 \mathrm{nmol} / 1 \mathrm{siRNA}$ & $0.23 \pm 0.05^{\mathrm{a}}$ \\
\hline
\end{tabular}

${ }^{\mathrm{a}} \mathrm{P}<0.01$ vs. negative control group.

concentrations of siRNA-1 $(50,80$ or $100 \mathrm{nmol} / \mathrm{l})$ or negative control siRNAs, and the extent of hTERT expression knockdown was determined. No significant difference was detected in the levels of hTERT mRNA between the $50 \mathrm{nmol} / \mathrm{l}$ and negative control groups $(\mathrm{P}>0.05)$, while the 80 - and $100-\mathrm{nmol} / \mathrm{l}$ groups showed significant reductions in hTERT mRNA levels compared to the control group $(\mathrm{P}<0.01)$. The difference in hTERT knockdown between the 80 - and 100-nmol/1 groups was not significantly different $(\mathrm{P}>0.05$; Table $\mathrm{V})$

Detection of the apoptotic fraction in hTERT siRNA-expressing lung cancer cells. The effect of hTERT knockdown on cancer cell apoptosis was analyzed by flow cytometry. As shown in Fig. 6 , the right lower quadrant (FITC+, PI-) shows early apoptotic cells, whereas the right upper quadrant (FITC+, PI+) shows late apoptotic cells. The apoptotic fraction was determined by adding the early apoptotic fraction to the late apoptotic 
A

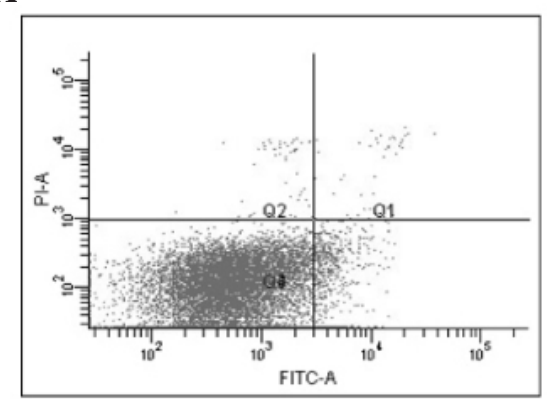

D

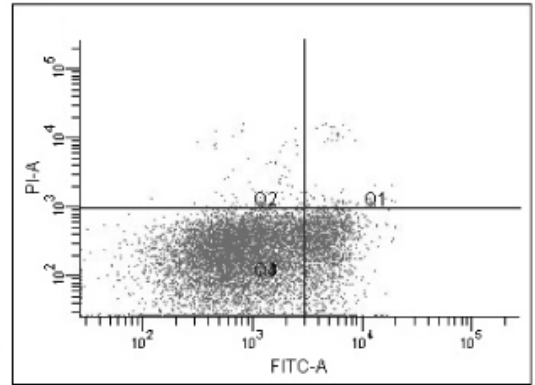

B

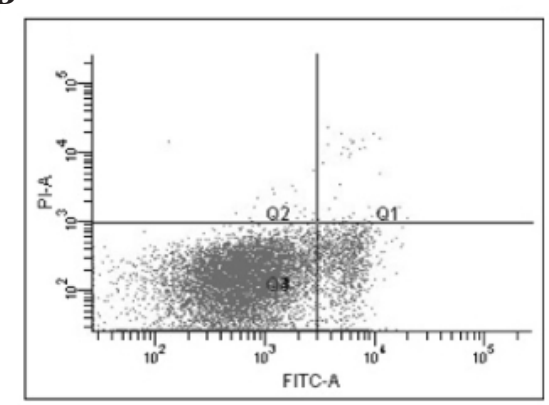

E

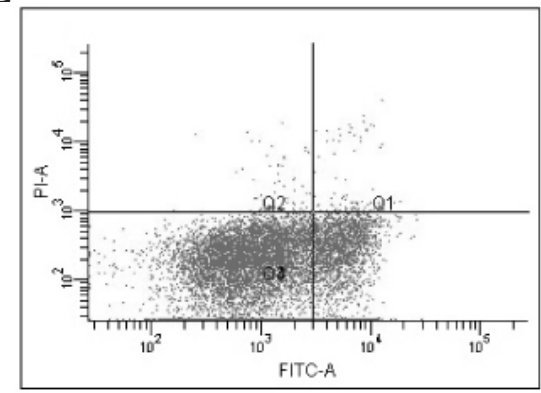

C

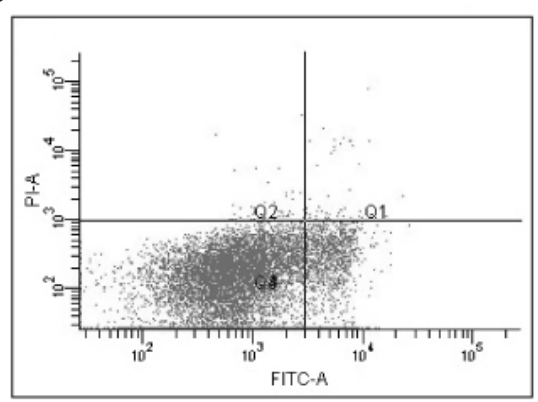

Figure 6. The effect of hTERT knockdown on cancer cell apoptosis was analyzed by flow cytometry. (A) siPORT NeoFX control, (B) negative control, (C) $50 \mathrm{nmol} / 1$ siRNA, (D) $80 \mathrm{nmol} / 1 \mathrm{siRNA}$ and (E) $100 \mathrm{nmol} / 1 \mathrm{siRNA}$.

Table VI. The effect of hTERT siRNA on cell apoptosis in 95D cells.

\section{Groups}

\section{siPORT NeoFX control}

Negative control

$50 \mathrm{nmol} / \mathrm{l} \mathrm{siRNA}$

$80 \mathrm{nmol} / \mathrm{l}$ siRNA

$100 \mathrm{nmol} / \mathrm{l} \mathrm{siRNA}$

${ }^{a} \mathrm{P}<0.01$ vs. siPORT NeoFX control group; ${ }^{\mathrm{b}} \mathrm{P}<0.05$ vs. siPORT NeoFX control group; ${ }^{\mathrm{P}}<0.01$ vs. negative control group.

fraction; apoptotic fractions of cells in different groups are shown in Table III. Compared with cells transfected with liposome alone, the apoptotic fractions in cells transfected with 50, 80 and $100 \mathrm{nmol} / 1$ hTERT siRNA-1 were significantly increased $(\mathrm{P}<0.01)$. Compared with cells transfected with the negative control siRNAs, the apoptotic fraction in the $50-\mathrm{nmol} / 1$ group was not significantly different $(\mathrm{P}>0.05)$, while the apoptotic fractions in the 80 - and $100-\mathrm{nmol} / \mathrm{l}$ groups were significantly increased $(\mathrm{P}<0.01)$. The apoptotic fraction was also significantly different between cells transfected with transfection reagent alone and cells transfected with the negative control siRNA $(\mathrm{P}<0.05$; Table VI), suggesting an inherent apoptotic effect of siRNA transfection on the target cells.

The effect of hTERT expression knockdown on lung cancer cell proliferation. MTT assays were performed to determine the proliferative effects of hTERT expression knockdown on lung cancer cells, and the results are shown in Fig. 3. At $12 \mathrm{~h}$ post-hTERT siRNA transfection, no significant inhibition of 95D cell proliferation was detected when compared to the negative control $(\mathrm{P}>0.05)$, but a significant inhibitory effect was detected at $24 \mathrm{~h}$ post-transfection and was enhanced at $48 \mathrm{~h}$; the reduction in proliferation was attenuated at $72 \mathrm{~h}$ post-transfection. The inhibition rate in the hTERT siRNAtransfected cells was significantly different from that in the negative control cells at 24,48 and $72 \mathrm{~h}$ post-transfection $(\mathrm{P}<0.05)$ in that the inhibitory effect of hTERT siRNA on cell proliferation was significantly higher at $48 \mathrm{~h}$ post-transfection when compared to that at 12,24 and $72 \mathrm{~h}$ post-transfection $(\mathrm{P}<0.01)$.

\section{Discussion}

The single copy hTERT gene is $41878 \mathrm{bp}$ in length and is located on chromosome 5p15.33; the length of its coding region is $4018 \mathrm{bp}$. We designed specific primers based on the hTERT sequence and examined hTERT mRNA expression in a variety of lung cancer cells by real-time RT-PCR. The results showed that the hTERT mRNA expression was relatively high in a variety of lung cancer cells, whereas the highest level of hTERT expression was detected in the highly metastatic 95D human giant-cell lung carcinoma cell line, followed by NCI-H460 cells, which are also large-cell lung carcinoma cells. Compared to squamous cell carcinoma and adenocarcinoma, the incidence of large-cell lung cancer is not high, but it is an occult cancer that develops rapidly, has poor treatment efficacy and prognosis and has a high degree of malignancy. The World Health Organization classifies giant-cell and clear-cell carcinomas as two subtypes of largecell lung cancer, and the pathological morphology, classification and development of the two subtypes are relatively complex (7). 
Most cells found in large-cell lung cancer are of neuroendocrine origin; therefore, this cancer is also known as large-cell neuroendocrine carcinoma (LCNEC). LCNEC, together with typical and atypical carcinoid and small-cell lung carcinoma, constitutes bronchopulmonary neuroendocrine tumors (8). These tumor cells, derived from the neuroendocrine cells in bronchial lung epithelia, have a characteristic microscopic morphology and biological behavior and have been a focus of cancer research in recent years.

Currently, there are numerous immunomarkers used to detect bronchopulmonary neuroendocrine tumors, most commonly neuron-specific enolase, synaptophysin and chromogranin A, although each has a different sensitivity and specificity (9). Therefore, searching for the best panel of immunomarkers to detect the differentiation of neuroendocrine tumors is crucial. Less than $10 \%$ of typical and atypical carcinoid tumors manifest telomerase activity, while $90 \%$ of both small-cell lung cancers and LCNEC show active telomerase (3). Telomerase-positive tumor cells often have high proliferation indices and a high degree of malignancy (10). In this study, the cell line with the highest relative expression of hTERT mRNA was a highly metastatic large-cell lung cancer line of immortalized cells with a high proliferation rate that was able to be passaged for a number of generations. Considering the biological characteristics of LCNEC, hTERT may be a significant marker in the detection of malignant lung cancer, particularly the marker for bronchopulmonary tumors with a high degree of malignancy and the characteristics of neuroendocrine tumors. It is obvious that hTERT is a tumor marker with high sensitivity and specificity. The detection of hTERT in combination with the histopathological examination of lung tumors may provide an early reference in diagnosing lung cancer and its potential for recurrence.

Since hTERT expression regulates telomerase activity in normal and tumor cells, hTERT is a key factor in determining telomerase activity in the cell and may be a target for tumor eradication. Therefore, siRNAs specifically targeting hTERT may down-regulate telomerase activity, induce apoptosis of cancer cells and inhibit cancer cell proliferation by reducing hTERT expression. Kosciolek et al (11) studied hTERT in various human cancer cells using RNAi and found that siRNAs efficiently and specifically inhibited the level of hTERT mRNA and, in turn, reduced telomerase activity by greater than $70 \%$. Other reports have confirmed that siRNAs inhibit hTERT expression in liver and breast cancer and leukemia cells, and inhibit the proliferation of cancer cells (12). In this study, we used specific siRNAs targeting hTERT and found that the decrease in hTERT expression negatively affected lung cancer cell growth and apoptosis.

The proper and rational design and synthesis of siRNAs is critical to the success of RNAi experiments. In addition to the conventional theoretical factors such as $\mathrm{G}+\mathrm{C}$ content, fragment length and the avoidance of homology with other coding sequences, attention should be paid to four principles. First, siRNA-binding sites should be located further than 50 to $100 \mathrm{bp}$ downstream of the start codon in the target sequence. Additionally, there should not be a large amount of repeat sequences. The sequences in the 5' and 3' untranslated regions and the region near the start codon should be avoided since these regions are rich in regulatory protein-binding sites.
These non-coding region-binding proteins or translation initiation complexes may affect RNA-induced silencing complex formation and the ability of the complex to bind mRNA, which weakens the effect of RNAi. Second, beginning from the AUG start codon in the mRNA sequence, 'AA' repeat sequences should be identified, since the 19 nucleotides at the 3 ' end of this repeat sequence are potential effective siRNA targeting sites. Third, the $3^{\prime}$ end should be designed to contain dTdT or dTdG overhangs to increase the stability of the siRNA molecules and to improve their resistance to degradation by ribozymes, thereby prolonging the knockdown effect. The fourth principle is that negative and positive control siRNAs should be included. Negative control siRNA sequences should have an identical or a similar composition as the selected siRNA, but show no degradative effect on the target mRNA $(13,14)$. The purpose of designing a positive control is to optimize transfection and detection conditions. Housekeeping genes are favorable positive controls in most cells. We used GAPDH-specific siRNAs as the positive control in the preliminary experiments. After GAPDH siRNAs were transfected into the target cells, GAPDH mRNA expression was significantly suppressed by over $85 \%$ compared to non-transfected cells; these data aided in determining the appropriate transfection conditions and experimental methods for the hTERT RNAi experiments.

Specific siRNAs only interfere with hTERT mRNA expression after entering the cells, and highly efficient siRNA transfection into the lung cancer cells was therefore of particlar significance to these experiments (15). Methods of transfecting siRNAs include calcium phosphate precipitation, electroporation, microinjection, DEAE-dextran and polybrene polymer complex methods and cationic liposomal delivery methods. Although most of these methods are characterized by low transfection efficacy, high cytotoxicity, poor reproducibility and a narrow range of applications, the cationic liposomal method has been widely used due to the ease of use, widespread application, high transfection efficacy and nonimmunogenicity. Although certain studies have achieved very high transfection efficiencies by using retroviral or adenoviral vector-mediated siRNA delivery $(16,17)$, the biological safety of these methods requires further study. In our experiments, siRNAs were transiently transfected using siPORT NeoFX, which is an inert liposomal reagent that can be effectively used for adherent cell transfection without obvious cytotoxicity. We also used the reverse transfection method (18), in which, instead of the conventional transfection where cells are plated in advance and the transfection reagent and siRNAs are added once the cells grow to a certain confluence, the cells in suspension are plated into wells that already contain the siRNA complexes and are allowed to adhere and expand. We used fluorescence microscopy to monitor the cell plating and transfection efficacy, which for 95D lung cancer cells was greater than $90 \%$. Thus, compared with the conventional transfection method, the reverse transfection method is timeefficient and increases the transfection efficacy, which may be due to the larger area of the non-adherent cells to which the siRNA transfection complexes bind. No significant change in cell morphology following transfection was observed, suggesting a lack of obvious cytotoxicity. Therefore, the reverse transfection method may be suitable for high-throughput siRNA transfection. 
After hTERT siRNAs were effectively transfected into 95D lung cancer cells, real-time RT-PCR was employed to measure the hTERT mRNA levels to confirm RNAi-induced hTERT knockdown. According to previous in vitro studies in mammalian cells, RNAi exhibited a time-dependent effect following the transfection of chemically synthesized siRNAs (19). This effect appeared at $12 \mathrm{~h}$ post-transfection, reached maximal knockdown at $48 \mathrm{~h}$ and gradually decreased after $72 \mathrm{~h}$. Based on our results, we selected $48 \mathrm{~h}$ post-transfection, at which point the most significant hTERT knockdown was measured as the detection time point in our experiments. The results showed that siRNA-1 and siRNA-2 significantly suppressed hTERT mRNA levels at $48 \mathrm{~h}$ post-transfection, with suppression rates of $77.33 \pm 5.13$ and $50.67 \pm 8.02 \%$, respectively, whereas siRNA-3 showed a relatively low suppression rate of $27.67 \pm 10.26 \%$. Based on these data, siRNA-1 was selected for our RNAi experiments.

In addition to the conventional blank control group in our experiments, the negative control and the liposome alone control groups were also included in our experiments and were critical in determining the specificity of RNAi. The negative control group used non-specific siRNAs and was included to exclude any effects caused by non-specific siRNAs on gene silencing. The liposome alone control group was used to identify potential effects of the transfection reagent on the experimental results. The results showed that, compared to the negative control and the liposome alone control groups, hTERT siRNA transfection groups using 80 and $100 \mathrm{nmol} / \mathrm{l}$ significantly reduced hTERT mRNA expression, whereas the transfection group with $50 \mathrm{nmol} / \mathrm{l}$ hTERT siRNA was not statistically different from the two control groups. These data demonstrate a concentration-dependent effect of hTERT siRNA on hTERT mRNA expression. Therefore, the siRNAmediated hTERT suppression can be enhanced with increased concentrations of siRNA.

RNAi targeting hTERT expression inhibited the growth of lung cancer cells and induced cell apoptosis. Data from MTT assays showed significant growth inhibition at $24 \mathrm{~h}$ posttransfection; this inhibition reached maximum levels at $48 \mathrm{~h}$ and then began to attenuate, which is consistent with the timedependent effect of siRNA on hTERT mRNA levels. These data are consistent with the hypothesis that the siRNA-dependent down-regulation of hTERT expression inhibits telomerase activity, promotes the progressive shortening of telomeres and thus effectively inhibits tumor cell growth. These data further suggest that hTERT is the rate-limiting factor of telomerase activity and is a favorable target of RNAi.

Flow cytometry revealed that lung cancer cells undergo apoptosis and necrosis following the suppression of hTERT mRNA expression (20). At $48 \mathrm{~h}$ post-transfection, apoptosis was detected in lung cancer cells and the apoptotic fraction was up to $22.87 \pm 3.37 \%$, although the increase in the apoptotic fraction was not as significant as that of the suppression rate of hTERT mRNA. The reason for this difference may be that the change in telomerase activity may not directly affect apoptosis, which is jointly regulated by a complex pathway composed of a variety of pro- and anti-apoptotic genes jointly. In addition, some investigators have identified a so-called telomere extension bypass in cancer cells, which is the alternative pathway of telomere extension. Although the exact mechanisms remain to be elucidated, this bypass may maintain telomeric integrity through DNA recombination to inhibit cell apoptosis and promote cell immortalization (21). Therefore, the clinical application of hTERT siRNA for the treatment of lung cancer may require other confirmed apoptosis-inducing agents.

This study used chemically synthesized siRNAs to perform in vitro RNAi experiments using lung cancer cells. Chemical synthesis technology is established, easy to operate and has wide applications; however, the chemically synthesized siRNAs are susceptible to RNase degradation and therefore have shorter durations for RNAi of no longer than 7 days (22). Our ultimate aim in using RNAi is to effectively treat lung cancer, which requires the continuous action of siRNAs in vivo. Methods used to express siRNAs in vivo include using siRNA expression cassettes (SECs) and siRNA expression vectors. SECs contain the siRNA expression template obtained by PCR, and the PCR product can be transfected directly into cells for expression without first being cloned into a vector (23). However, since it is difficult to transfect PCR products into cells and the PCR products do not contain drug resistance genes, stable cell transfection cannot be conducted, as the in vivo biological function is transient and is not suitable for long-term suppression $(24,25)$. The aim of using siRNA expression vectors is to generate intracellular siRNAs through a plasmid or viral vector to achieve long-term suppression of target gene expression. The antibiotic selection marker on the siRNA expression vector aids in the rapid selection of siRNApositive clones and may be the ideal approach for a wide array of in vivo RNAi research applications and treatment strategies.

In conclusion, hTERT is a key regulator of telomerase activity and is potentially a tumor marker for lung cancer detection. hTERT was highly expressed in multiple lung cancer cell lines of different pathological types, and the highest relative expression levels were found in large-cell lung carcinoma cells. The significant reduction in hTERT mRNA by RNAi induced apoptosis and inhibited the proliferation of 95D lung cancer cells, suggesting that telomerase activity is closely associated with tumor cell survival and proliferation. These data further suggest that telomerase is a key target for RNAi-based lung cancer strategies.

\section{References}

1. Raynaud CM, Sabatier L, Philipot O, Olaussen KA and Soria JC: Telomere length, telomeric proteins and genomic instability during the multistep carcinogenic process. Crit Rev Oncol Hematol 66: 99-117, 2008.

2. Djojosubroto MW, Choi YS, Lee HW and Rudolph KL: Telomeres and telomerase in aging, regeneration and cancer. Mol Cells 15: 164-175, 2003.

3. Taga S, Osaki T, Ohgami A, Imoto H and Yasumoto K: Prognostic impact of telomerase activity in non-small cell lung cancers. Ann Surg 230: 715-720, 1999.

4. Hiyama K, Hiyama E, Ishioka S, Yamakido M, Inai K, Gazdar AF, Piatyszek MA and Shay JW: Telomerase activity in small-cell and non-small cell lung cancers. J Natl Cancer Inst 87: 895-902, 1995.

5. Livak KJ and Schmittgen TD: Analysis of relative gene expression data using real-time quantitative PCR and the 2(-Delta Delta C(T)) Method. Methods 25: 402-408, 2001.

6. Xia Y, Lin RX, Zheng SJ, Yang Y, Bo XC, Zhu DY and Wang SQ: Effective siRNA targets screening for human telomerase reverse transcriptase. World J Gastroenterol 11: 2497-2501, 2005.

7. The World Health Organization histological typing of lung tumours. Second edition. Am J Clin Pathol 77: 123-136, 1982. 
8. Schleusener JT, Tazelaar HD, Jung SH, Cha SS, Cera PJ, Myers JL, Creagan ET, Goldberg RM and Marschke RF Jr: Neuroendocrine differentiation is an independent prognostic factor in chemotherapy-treated nonsmall cell lung carcinoma. Cancer 77: 1284-1291, 1996.

9. Graziano SL, Tatum AH, Newman NB, Oler A, Kohman LJ, Veit LJ, Gamble GP, Coleman MJ, Barmada S and O'Lear S: The prognostic significance of neuroendocrine markers and carcinoembryonic antigen in patients with resected stage I and II non-small cell lung cancer. Cancer Res 54: 2908-2913, 1994.

10. Zaffaroni N, De Polo D, Villa R, Della Porta C, Collini P, Fabbri A, Pilotti S and Daidone MG: Differential expression of telomerase activity in neuroendocrine lung tumours: correlation with gene product immunophenotyping. J Pathol 201: 127-133, 2003 .

11. Kosciolek BA, Kalantidis K, Tabler M and Rowley PT: Inhibition of telomerase activity in human cancer cells by RNA interference. Mol Cancer Ther 2: 209-216, 2003.

12. Zhou $X$ and Zhang PH: Stable inhibition of hTERT gene by siRNA in hepatocarcinoma cells. J Fourth Mi1 Med Univ 26 2233-2236, 2005.

13. Reynolds A, Leake D, Boese Q, Scaringe S, Marshall WS and Khvorova A: Rational siRNA design for RNA interference. Nat Biotechnol 22: 326-330, 2004.

14. Ui-Tei K, Naito Y, Takahashi F, Haraguchi T, Ohki-Hamazaki H, Juni A, Ueda R and Saigo K: Guidelines for the selection of highly effective siRNA sequences for mammalian and chick RNA interference. Nucleic Acids Res 32: 936-948, 2004.

15. Pham JW, Pellino JL, Lee YS, Carthew RW and Sontheimer EJ: A Diecr-2- dependent 80s complex cleaves targeted mRNAs during RNAi in Drosophila. Cell 117: 83-94, 2004.
16. Godfrey A, Anderson J, Papanastasiou A, Takeuchi Y and Boshoff C: Inhibiting primary effusion lymphoma by lentiviral vectors encoding short hairpin RNA. Blood 105: 2510-2518, 2005.

17. Andersson MG, Haasnoot PC, Xu N, Berenjian S, Berkhout B and Akusjärvi G: Suppression of RNA interference by adenovirus virus-associated RNA. J Virol 79: 9556-9565, 2005.

18. Erfle H, Neumann B, Liebel U, Rogers P, Held M, Walter T, Ellenberg J and Pepperkok R: Reverse transfection on cell arrays for high content screening microscopy. Nat Protoc 2: 392-399, 2007.

19. He GP, Zhang SZ, Wang YC, Xiao CY, Ma YX, Xu WM, Ding L, Tao DC, Sun Y and Chen YJ: Time and dose effect of RNA interference mediated by short hairpin RNA. Progress in Biochemistry and Biophysics 32: 258-267, 2005.

20. Shammas MA, Koley H, Batchu RB, Bertheau RC, Protopopov A, Munshi NC, Goyal RK: Telomerase inhibition by siRNA causes senescence and apoptosis in Barrett's adenocarcinoma cells: mechanism and therapeutic potential. Mol Cancer 4: 24, 2005.

21. Collins K and Mitchell JR: Telomerase in the human organism. Oncogene 21: 564-579, 2002.

22. Martinez J, Patkaniowska A, Urlaub H, Lührmann R and Tuschl T: Single-stranded antisense siRNAs guide target RNA cleavage in RNAi. Cell 110: 563-574, 2002.

23. Castanotto D, Li HT and Rossi IJ: Functional siRNA expression form transfected PCR products. RNA 8: 1454-1460, 2002.

24. Wu N, Gu HJ and Li Q: Effects of antidiabetic drug metformin on the migration and invasion abilities of human pulmonary adenocarcinoma A549 cell line in vitro. J Thorac Dis 2: 76-78, 2010.

25. Shao WL, Wang DY and He JX: The role of gene expression profiling in early-stage non-small cell lung cancer. J Thorac Dis 2: 89-99, 2010. 